\title{
Differential effects of ethnic density on the risk of postnatal depression and personality dysfunction
}

\author{
Andrea Du Preez, Susan Conroy, Susan Pawlby, Paul Moran* and Carmine M. Pariante*
}

\section{Background}

The relationship between ethnic density and psychiatric disorder in postnatal women in the UK is unclear.

\section{Aims \\ To examine the effect of own and overall ethnic density on postnatal depression (PND) and personality dysfunction. \\ Method \\ Multilevel analysis of ethnically mixed community-level data gathered from a sample of 2262 mothers screened at 6 weeks postpartum for PND and personality dysfunction. \\ Results \\ Living in areas of higher own ethnic density was protective against screening positive for PND in White women $(z=-3.18, P=0.001)$, even after adjusting for area level deprivation, maternal age, relationship status, screening}

positive for personality dysfunction, parity and geographical clustering (odds ratio (OR) $0.98(95 \% \mathrm{Cl} 0.96-0.99) ; P=0.002)$ whereas the effect on personality dysfunction $(z=-2.42$, $P=0.016)$ was no longer present once the effect of PND was taken into account $(\mathrm{OR}=0.99(95 \% \mathrm{Cl} 0.90-1.0) ; P=0.13)$. No overall ethnic density effect was found for women screening positive for PND or personality dysfunction.

\section{Conclusions}

In White women, living in areas of higher own ethnic density was protective against developing PND.

\section{Declaration of interest}

None.

\section{Copyright and usage}

(c) The Royal College of Psychiatrists 2016.
Ethnic density is increasingly recognised as an important correlate of mental health in the UK. Black and minority ethnic (BME) individuals living in areas with high levels of own and overall BME concentration, irrespective of the level of deprivation, exhibit better mental health outcomes. ${ }^{1-3}$ Understanding how this phenomenon exerts positive or protective effects on mental health may be the key to alleviating some of the prevalence differences found among ethnic groups. For example, research has shown how belonging to a BME group, especially from an Asian population, or being born in a non-English-speaking country, are significant risk factors for developing postnatal depression (PND) in London. ${ }^{4}$ Specifically, when compared with White British and White Irish populations, the prevalence of PND is significantly higher among Indian, Pakistani and Black Caribbean populations. ${ }^{5}$ Ethnic differences have also been demonstrated in personality disorder, with higher prevalence rates among Black and other ethnic minority groups. ${ }^{6}$ With the UK becoming more ethnically diverse, understanding the precise mechanisms leading to these differences, and what can be done to alleviate them, has therefore become increasingly important.

To date, no study has examined the effect of ethnic density on personality disorder, and only one study has examined the effect of ethnic density in women with PND, finding no significant association between ethnic density and PND in BME women.? However, this study did not include a White sample, and a single question was used to screen women with PND, both of which may represent limitations. Therefore, there is a need to explore the ethnic density effect in personality disorder and PND.

Both PND and personality disorder are relatively common conditions: personality disorder is estimated to have a weighted prevalence of $4 \%,{ }^{8}$ whereas clinically diagnosed depression, from birth to 2 months postpartum, has a period prevalence of $6 \% .{ }^{9}$ Moreover, PND and personality disorder frequently co-occur, ${ }^{10,11}$

*These authors contributed equally to this work. further reinforcing the importance of determining whether an ethnic density effect exists for either disorder.

With all this in mind, we aimed to clarify the relationship between ethnic density and PND, and sought to determine whether an ethnic density effect operates for personality dysfunction, representative of subclinical personality disorder, in order to extend the frontiers of this area of research. Specifically, we aimed to (a) test whether the ethnic density effect is groupspecific (i.e. own ethnic density) or simply the result of living among other ethnic populations (i.e. overall ethnic density); (b) examine whether ethnic density correlates linearly with the severity of each disorder; and (c) determine the diagnostic specificity of this putative effect, by investigating the effect on both PND and personality dysfunction, and specifically whether this effect would differ according to whether the diagnosis was short term, as in the case of PND, or long term, with respect to personality dysfunction.

\section{Method}

\section{Sampling and participants}

Analyses for this study were conducted using data collected as part of the Early Infant Care Study (EICS), which was approved by the relevant local research ethics committees. As described extensively before, ${ }^{12}$ the EICS recruited newly delivered women between 2004 and 2006, from the postnatal wards at King's College Hospital, a large teaching hospital in London primarily serving the boroughs of Lambeth, Southwark and Lewisham, whose populations are sociodemographically and ethnically mixed, and with high levels of psychiatric morbidity. Women were excluded if they had: poor English fluency; had had a multiple birth, a gestation length less than 36 weeks; a baby with a birth weight below $2000 \mathrm{~g}$; or if they had experienced any immediate postnatal complications. Of the 3142 eligible women approached, 2644 (84\%) agreed to participate, and a sociodemographic schedule 
enquiring about maternal age, marital status, ethnicity and several infant and delivery features were administered at recruitment. Of those recruited, $2262(86 \%)$ were screened for both PND and personality dysfunction, at 6 weeks postpartum.

The 9-item depression module from the Patient Health Questionnaire (PHQ-9) ${ }^{13}$ is an open-access diagnostic instrument for depression used in different healthcare and community settings, including the general population. ${ }^{14,15}$ It can be used to monitor the severity of depression and response to treatment ${ }^{13}$ and has been validated in BME groups. ${ }^{16}$ The PHQ-9 has also been commonly used to screen for depression, with a sensitivity and specificity of $88 \%$ for major depression. ${ }^{13}$ In this study, the PHQ-9 was used to screen for PND, which was considered to be present if the total PHQ-9 score was $\geqslant 12$, which has better diagnostic properties than a cut-off score of $10 .{ }^{17,18}$

The Standardised Assessment of Personality - Abbreviated Scale (SAPAS) $)^{19}$ is a brief interview-based screening instrument for personality dysfunction, ${ }^{20,21}$ consisting of eight dichotomously rated items. In this study, as in line with previous research, ${ }^{21}$ a cut-off score of four was used to identify women with personality dysfunction. A cut-off of four has a slightly better positive predictive value when the prevalence in the population is assumed to be low, an assumption that befits our community sample. The SAPAS has also been used in studies with ethnically diverse samples ${ }^{6,21,22}$ and has a sensitivity of $82 \%$ and specificity of $89 \%$ when a cut-off score of four or more is used. ${ }^{19}$

\section{Individual-level measures}

Ethnicity for all women was defined according to self-report criteria as used in the UK census. ${ }^{23}$ Since there were too few respondents from each of the official 16 categories used in the UK census to allow detection of any significant associations in some analyses (not shown), ethnicity was categorised into two main groups, 'White' and 'BME'. Therefore, findings based on these two categories only are presented here. White constitutes all White British, White Irish and White Other women, and BME encompasses the remaining 13 ethnic categories.

Three other maternal features were examined: maternal age, relationship status and parity. Relationship status was classified as cohabiting/married, non-cohabiting/non-marital or single, whereas parity was defined as either primiparous or multiparous. Five infant and delivery features were also examined: mode of delivery (vaginal, elective Caesarean or emergency Caesarean), infant gender, gestational length, birth weight and whether the infant was admitted to the neonatal unit.

\section{Area-level measures}

Under the terms of the Open Government Licence and UK Government Licensing Framework, the participants' postcode data-set was linked to the 2001 UK census ${ }^{24}$ in order to obtain data on ethnic density. Each postcode was matched to its respective lower super output area (LSOA) using an online geography matching and conversion tool called GeoConvert (Mimas UDS. GeoConvert, UK Data Service, Essex, UK; see http://geoconvert.mimas.ac.uk/). LSOAs are used to define area boundaries, and are the lowest level of disaggregation, representing the smallest geographical areas within the UK, and comprising between 400 and 1000 households. ${ }^{25}$

Own ethnic density refers to the proportion of individuals from the respondent's ethnic group in a defined area, divided by the total population in that area. Essentially, it is the concentration of co-ethnics in a defined area. It was calculated as the number of residents in an ethnic group in each LSOA, divided by the total
LSOA population. Overall ethnic density refers to the proportion of all BME individuals in an area, divided by the total population in that area. Unlike own ethnic density, it refers to the concentration of all individuals from any BME background in a defined area. In accordance with previously published research, overall ethnic density was calculated as the number of all BME groups, excluding White minority ethnic groups, in each LSOA, divided by the total LSOA population. ${ }^{26}$

The Index of Multiple Deprivation (IMD) ${ }^{27}$ from 2004 was used to measure area-level deprivation and matched to LSOA. IMD represents a multiple deprivation score based on seven individual domains: income, health deprivation and disability, employment disadvantage, education, skills and training, poor access to housing and services, poor indoor and outdoor living environment, and crime levels. ${ }^{27}$ The lower the IMD score, the less deprived the area. IMD was analysed as a continuous score in all analyses.

\section{Statistical analysis}

Analyses were performed using SPSS version 21 for Windows. Characteristics of the sample were compared using chi-squared tests for categorical variables and independent samples $t$-tests for continuous variables. Area-level deprivation, maternal age, ethnicity, parity, marital status and infant/delivery features were analysed as a priori confounders, using regression analysis. Associations between own and overall ethnic density and mental health outcomes were initially analysed using Mann-Whitney $U$-tests. To determine whether own and overall ethnic density were independently associated with PND and personality dysfunction, regression analyses were conducted. To allow the modelling of variance at individual- and area-level, and to account for geographical clustering, multilevel regression analyses were performed, using the PHQ-9 and SAPAS as continuous variables. LSOA was specified as the grouping variable, with individuals nested within these areas. Two level multilevel models with random intercepts and fixed effects for each predictor were specified, and the ethnic density variables were transformed using a square root transformation to meet all required assumptions of the linear model. Logistic regression, using robust standard errors to account for any non-independence caused by geographical clustering, were used to model the effects of ethnic density on screening positive for PND and for personality dysfunction. Separate parsimonious models were conducted for each ethnic group and for each mental health outcome.

\section{Results}

\section{Participant characteristics}

The demographic features for the interviewed sample $(n=2262)$ are shown in Table 1. Compared with White women, mothers from the BME group were more likely to be single $\left(\chi_{(2)}^{2}=184.4, P<0.001\right)$, under the age of 25 years $\left(\chi_{(1)}^{2}=50.07, P<0.001\right)$, to be multiparous $\left(\chi_{(1)}^{2}=26.42, P<0.001\right)$, have an emergency Caesarean $\left(\chi_{(2)}^{2}=6.89, P=0.032\right)$, have a baby with a lower birth weight $\left(t_{(2,256)}=7.65, \quad P<0.001\right)$, have a shorter gestational length $\left(t_{(2,258)}=4.41, P<0.001\right)$ and live in a more deprived area $\left(t_{(2,187)}=-14.79, P<0.001\right)$.

\section{Prevalence of PND and personality dysfunction}

The ethnic breakdown and associated prevalence rates for PND and personality dysfunction for all 16 ethnic groups are shown in online Table DS1. For the sample as a whole, the weighted prevalence of screening positive for PND only was $2.3 \%$, for 


\begin{tabular}{|c|c|c|c|}
\hline \multirow[b]{2}{*}{ Sociodemographic features } & \multicolumn{3}{|c|}{ Unweighted $n$} \\
\hline & $\begin{array}{c}\text { Total } \\
(n=2262)\end{array}$ & $\begin{array}{l}\text { White }^{\mathrm{a}} \\
(n=1040)\end{array}$ & $\begin{array}{l}\text { Black and minority ethnic } \\
\qquad(n=1222)\end{array}$ \\
\hline \multicolumn{4}{|l|}{ Maternal features } \\
\hline \multicolumn{4}{|l|}{ Mother's age, $n(\%)$} \\
\hline Under 25 years & $316(20)$ & $90(12)$ & $226(27)^{\star \star \star}$ \\
\hline Mean (s.d.) & 30.5 (6.3) & $32(5.7)$ & $29.2(6.4)^{\star * *}$ \\
\hline \multicolumn{4}{|l|}{ Relationship status, $n$ (\%) } \\
\hline Single & $271(12)$ & $51(5)$ & $220(18)^{* * *}$ \\
\hline Non-marital/non-cohabiting & $244(11)$ & $51(5)$ & $193(16)$ \\
\hline Married/cohabiting & $1746(77)$ & $938(90)$ & $808(66)$ \\
\hline \multicolumn{4}{|l|}{ Parity, $n(\%)$} \\
\hline Primiparous & $1308(58)$ & $661(64)$ & $647(53)$ \\
\hline Multiparous & $954(42)$ & $379(36)$ & $575(47)^{\star \star *}$ \\
\hline \multicolumn{4}{|l|}{ Infant and delivery features } \\
\hline Male baby, $n(\%)$ & 1209 (53) & $555(53)$ & $654(54)$ \\
\hline Baby admitted to SCBU, $n$ (\%) & $201(9)$ & $97(9)$ & $104(9)$ \\
\hline \multicolumn{4}{|l|}{ Mode of delivery, $n(\%)$} \\
\hline Vaginal & $1493(66)$ & $702(68)$ & $791(65)$ \\
\hline Elective Caesarean & $217(10)$ & $109(10)$ & $108(9)$ \\
\hline Emergency Caesarean & $482(21)$ & $198(19)$ & $284(23)^{* * *}$ \\
\hline Gestational age, weeks: mean (s.d.) & $39.8(1.5)$ & $39.9(1.5)$ & $39.7(1.4)^{* * *}$ \\
\hline Birth weight, g: mean (s.d.) & $3374.4(519.6)$ & $3463.9(503.3)$ & $3298.3(521.1)^{* * *}$ \\
\hline \multicolumn{4}{|l|}{ Neighbourhood features } \\
\hline Deprivation (IMD) score, mean (s.d.) & $34(11.1)$ & $30.4(10.7)$ & $37.1(10.5)^{* * *}$ \\
\hline \multicolumn{4}{|c|}{$\begin{array}{l}\text { SCBU, special care baby unit; IMD, Index of Multiple Deprivation. } \\
\text { a. White British, White Irish and White Other. } \\
\text { b. All ethnic groups except the three White groups. } \\
\star \star \star P<0.001 \mathrm{~V} \text {. White women. }\end{array}$} \\
\hline
\end{tabular}

personality dysfunction only it was $12 \%$, and for comorbid diagnosis (both PND and personality dysfunction) it was $2.7 \%$. Compared with BME women, White mothers had significantly lower prevalence rates for PND $\left(1.3 \%\right.$ v. $4.9 \% ; \chi_{(1)}^{2}=5.70$, $P=0.017)$, for personality dysfunction $(6.7 \%$ v. $25.7 \%$; $\left.\chi_{(1)}^{2}=9.25, P=0.002\right)$, and for comorbid diagnosis $(1.2 \% v$. $\left.6.7 \% ; \chi_{(1)}^{2}=6.58, P=0.01\right)$.

\section{Sociodemographic factors associated with PND and personality dysfunction}

Women were significantly more likely to meet screening criteria for PND if they screened positive for personality dysfunction $\left(\chi_{(1)}^{2}=150.63, \quad P<0.001\right)$, were under 25 years of age $\left(\chi_{(1)}^{2}=5.134, \quad P=0.023\right)$, were multiparous $\left(\chi_{(1)}^{2}=5.72\right.$, $P=0.017)$, were single $\left(\chi_{(1)}^{2}=5.75, P=0.016\right)$ and were from the BME group $\left(\chi_{(1)}^{2}=5.97, P=0.017\right)$. With respect to personality dysfunction, women were significantly more likely to screen positive if they met screening criteria for $\operatorname{PND}\left(\chi_{(1)}^{2}=150.63\right.$, $P<0.001)$, were in a non-cohabiting/non-marital relationship $\left(\chi_{(1)}^{2}=14.11, P<0.001\right)$, were from the BME group $\left(\chi_{(1)}^{2}=9.25\right.$, $P=0.002)$ and lived in a more deprived area $\left(t_{(2,187)}=-2.54\right.$, $P=0.011)$ compared with women who were healthy. All aforementioned sociodemographic factors were controlled for in all subsequent analyses in relation to PND and personality dysfunction.

\section{Association between ethnic density, area-level deprivation and ethnicity}

In total there were 90 analysed LSOAs within our sample. White women in the sample had significantly higher median own ethnic density scores compared with BME mothers $(z=-26.62$, $P<0.001)$. The reverse association was seen between overall ethnic density and ethnicity, whereby White women had significantly lower median overall ethnic density scores compared with BME women $(z=-16.28, P<0.001)$.
Decreasing White population own ethnic density was significantly associated with increasing deprivation (Spearman's $r=-0.50, \quad n=1007, \quad P<0.001)$, whereas the opposite was observed for decreasing BME population ethnic density $(r=0.48, n=1165, P<0.001)$. Decreasing overall ethnic density was significantly associated with decreasing area-level deprivation in both White and BME populations (Spearman's $r=0.82$, $n=1007, P<0.001 ; r=0.71, n=1165, P<0.001$, respectively).

\section{Association between ethnic density and PND or personality dysfunction}

Table 2 shows the median own ethnic density concentrations for women screening positive for PND and personality dysfunction compared with women who were healthy. Women who screened positive for PND were more likely to live in areas of lower own ethnic density $(z=-3.81, P<0.001)$; the same effect was present for personality dysfunction $(z=-3.20, P<0.001)$. However, when women were divided by ethnic groups, only White women who screened positive for PND were more likely to live in areas of lower own ethnic density $(z=-3.18, P=0.001)$, and again the same effect was present for personality dysfunction $(z=-2.42, P=0.016)$; these effects were not present in BME women.

No statistically significant association was found between screening positive for PND or for personality dysfunction and overall ethnic density, for the sample as a whole, or specifically within the White and BME groups.

\section{Own ethnic density as a predictor for positive screening of PND in the multilevel regression model}

In the analyses described above, we have shown that lower own ethnic density was associated with an increased prevalence of PND and personality dysfunction, but only in White women. Moreover, we have shown that lower own ethnic density in White 
Table 2 Median scores of own and overall ethnic density for White and Black and minority ethnic women screening positive for postnatal depression and for personality dysfunction, compared with healthy women

\begin{tabular}{|c|c|c|c|c|}
\hline & \multicolumn{2}{|c|}{ Postnatal depression } & \multicolumn{2}{|c|}{ Personality dysfunction } \\
\hline & Healthy women & Women screening positive & Healthy women & Women screening positive \\
\hline \multicolumn{5}{|c|}{ Total sample } \\
\hline \multicolumn{5}{|c|}{ Median \% ethnic density (interquartile range) } \\
\hline Own & $17.1(7.1-52.2)(n=2067)$ & $10.5(4.3-23.7)^{* * *}(n=105)$ & $17.1(7.2-52.8)(n=1866)$ & $13.7(6.4-39.6)^{\star * *}(n=306)$ \\
\hline Overall & $36.6(28.9-47.6)(n=2067)$ & $36.4(28.4-46.8)(n=105)$ & $36.3(28.9-47.0)(n=1866)$ & $39.0(28.9-49.2)(n=306)$ \\
\hline \multicolumn{5}{|c|}{ White women } \\
\hline \multicolumn{5}{|c|}{ Median \% ethnic density (interquartile range) } \\
\hline Own & $53.2(13.8-61.9)(n=970)$ & $15.8(7.7-55.1)^{\star \star}(n=37)$ & $53.5(12.1-61.9)(n=890)$ & $45.2(9.8-59.0)^{*}(n=117)$ \\
\hline Overall & $31.3(24.8-40.1)(n=970)$ & $31.8(26.2-43.6)(n=37)$ & $31.3(24.8-39.7)(n=890)$ & $31.9(24.8-44.4)(n=117)$ \\
\hline \multicolumn{5}{|c|}{ BME women } \\
\hline \multicolumn{5}{|c|}{ Median \% ethnic density (interquartile range) } \\
\hline Own & $11.3(2.8-17.8)(n=1097)$ & $10.0(2.5-16.4)(n=68)$ & $11.3(2.9-17.8)(n=976)$ & $11.0(2.5-17.1)(n=189)$ \\
\hline Overall & $42.0(32.1-52.8)(n=1097)$ & $39.7(30.7-50.0)(n=68)$ & $41.6(32.0-52.8)(n=976)$ & $41.4(31.3-52.3)(n=189)$ \\
\hline
\end{tabular}

women was associated with increasing area-level deprivation; and that a younger age, being single, screening positive for personality dysfunction, being multiparous and belonging to the BME group were significantly associated with positive screening of PND. Being in a non-cohabiting/non-marital relationship, screening positive for PND, belonging to the BME group and living in areas with higher deprivation were significantly associated with personality dysfunction. To explore the different factors contributing to the association between own ethnic density and $\mathrm{PND} /$ personality

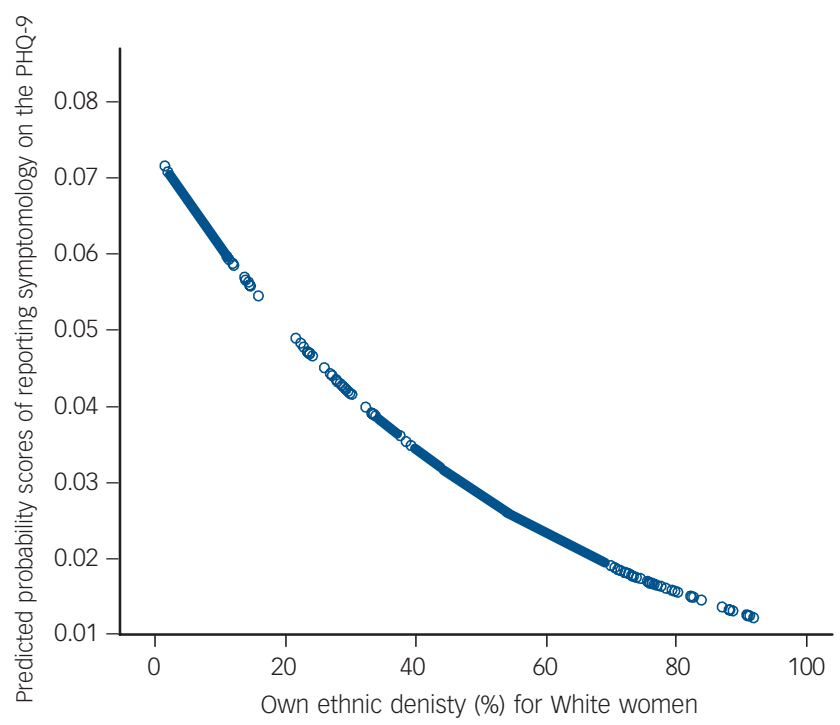

Fig. 1 Predicted probabilities for the association between own ethnic density and expected Patient Health Questionnaire-9 (PHQ-9) scores in the White group.

Model adjusts for maternal age, positive screen for personality dysfunction, deprivation, relationship status and parity, and takes into account area-leve clustering. dysfunction in White women, we conducted multilevel regression modelling.

Table 3 shows the multilevel regression results for the association between own ethnic density and PHQ-9 scores for White women. Living in areas of lower own ethnic density was significantly and independently associated with higher PHQ-9 scores, after adjusting for area-level deprivation, relationship status, maternal age, screening positive for personality dysfunction, parity and geographical clustering (Model 3). Figure 1 demonstrates that an increase in own ethnic density was associated with a decrease in the predicted probabilities of reporting depressive symptomology. Consistent with these findings, for White women, living in areas with higher own ethnic density was significantly and independently protective against screening positive for PND (odds ratio (OR) 0.98 (95\% CI 0.96-0.99); $P=0.002$ ).

With regard to personality dysfunction, Table 4 shows the multilevel regression results of the association between own ethnic density and SAPAS scores for White women. Living in areas of lower own ethnic density was significantly and independently associated with higher SAPAS scores, after adjusting for area-level deprivation and geographical clustering (Model 2). However, the association was no longer significant when taking into account relationship status and screening positive for PND (Model 3). On further analysis, screening positive for PND was found to be confounding this association; and robust logistic regression results confirmed no significant association between own ethnic density and screening positive for personality dysfunction for White women within the sample, once the effect of PND was taken into account $(\mathrm{OR}=0.99$ (95\% CI 0.90-1.0); $P=0.134)$.

\section{Discussion}

\section{Main findings}

We have examined the effects of ethnic density at the level of LSOA, i.e. the smallest geographical area within the UK,

\begin{tabular}{|c|c|c|c|}
\hline Own ethnic density & $\begin{array}{c}\text { Model } 1^{\text {a }} \\
\text { Estimate }(95 \% \text { confidence } \\
\text { intervals); s.e.; } P\end{array}$ & $\begin{array}{c}\text { Model } 2^{\mathrm{b}} \\
\text { Estimate ( } 95 \% \text { confidence } \\
\text { intervals); s.e.; } P\end{array}$ & $\begin{array}{c}\text { Model } 3^{\mathrm{c}} \\
\text { Estimate ( } 95 \% \text { confidence } \\
\text { intervals); s.e.; } P\end{array}$ \\
\hline Postnatal depression & $-0.16(-0.26$ to 0.06$) ; 0.05 ; 0.002$ & $-0.13(-0.24$ to 0.02$) ; 0.05 ; 0.018$ & -0.15 ( -0.27 to 0.03$) ; 0.06 ; 0.015$ \\
\hline
\end{tabular}




\begin{tabular}{|c|c|c|c|}
\hline Own ethnic density & $\begin{array}{c}\text { Model } 1^{\text {a }} \\
\text { Estimate (95\% confidence } \\
\text { intervals); s.e.; } P\end{array}$ & $\begin{array}{c}\text { Model } 2^{\mathrm{b}} \\
\text { Estimate }(95 \% \text { confidence } \\
\text { intervals); s.e.; } P\end{array}$ & $\begin{array}{c}\text { Model } 3^{\mathrm{C}} \\
\text { Estimate }(95 \% \text { confidence } \\
\text { intervals); s.e.; } P\end{array}$ \\
\hline Personality dysfunction & $-0.06(-0.10$ to -0.02$) ; 0.02 ; 0.002$ & $-0.05(-0.08$ to -0.01$) ; 0.02 ; 0.024$ & $-0.03(-0.07$ to 0.01$) ; 0.02 ; 0.120$ \\
\hline
\end{tabular}

comprising between 400 and 1000 households. Higher own ethnic density, i.e. living in an LSOA with a larger proportion of people from the same ethnic group, was protective against PND, but only for White women: women who are White British, White Irish and White Other. Interestingly, overall ethnic density, i.e. living in an area with a low or a high proportion of people from all BME groups, had no effect on the risk of PND, for either White or BME women. Moreover, ethnicity per se had no effect, after adjusting for other risk factors for PND. Finally, own or overall ethnic density did not independently predict whether women screened positive for personality dysfunction.

\section{Relationship to previous findings}

The findings of this study, which demonstrated that living in areas of higher own ethnic density is protective against common mental illness, are in line with previous research. ${ }^{3,28-30}$ Indeed, our data strengthen this notion, by showing for the first time that living in areas of higher own ethnic density is protective specifically in White women against developing PND, and even after adjusting for area-level deprivation, parity, relationship status and maternal age. Moreover, our finding that own ethnic density is specifically protective for White women and not BME women is, in fact, in agreement with previous findings showing an ethnic density effect for White populations only. ${ }^{30,31}$ Our finding that an ethnic density effect does not exist for BME women is also in line with previous research, ${ }^{7,32,33}$ and particularly with the only other study that has evaluated the association between own ethnic density and PND, which found no buffering effect of ethnic density in BME women. ${ }^{7}$

In addition to finding an own ethnic density effect, our data demonstrate that the effect is differential for overall ethnic density, and for personality dysfunction. The fact that there is no significant protective effect of living in areas of higher overall ethnic density emphasises that living among co-ethnics is ultimately what contributes to the driving mechanism of the ethnic density effect within our sample. This could be because social support is a very important factor for a woman vulnerable to $\mathrm{PND},{ }^{34-36}$ and so by living among co-ethnics, she may feel less isolated and form a stronger social network. Moreover, having a new baby is a challenging and life-changing event for most women, and one can see how, during those first few months where a woman is predominantly at home, the area in which she lives could influence her state of mind. However, this is the first study that examined the effects of both own and overall ethnic density on PND within the same sample; most research demonstrates a protective effect of high overall ethnic density in schizophrenia and mental health in general, ${ }^{37-40}$ but only four studies have demonstrated a protective effect of own ethnic density, again, in relation to psychosis and general mental health. ${ }^{3,28-30}$

Although we found that women who screened positively for personality dysfunction were more likely to live in areas of lower own ethnic density, multilevel regression modelling revealed that screening positive for PND confounded this association. Personality dysfunction is generally a long-term difficulty and our finding is consistent with other research which has failed to detect an association between ethnic density and other long-term conditions. ${ }^{30}$ However, we suspect that the main reason why personality dysfunction was impervious to the protective effects of ethnic density relates to the definition of personality disorder. One of the key defining features of personality disorder is poor interpersonal functioning, i.e. a general impairment in all human relationships. We hypothesise that this impairment is related to sheer proximity to other individuals, and is not specifically linked to a defining demographic feature of the other individual, such as their ethnicity.

Our findings demonstrate how a protective association between own ethnic density and PND exists for White women within the sample, but not for BME women. Indeed, there might be several putative reasons as to why no significant ethnic density effect was found within our BME women. First, within the sample there were very few BME women living in areas of higher own ethnic density, as confirmed by the narrow interquartile ranges (Table 2), making it less likely that significant differences associated with changes in own ethnic density concentrations would be detected within the BME group, especially if there were an ethnic density effect 'threshold'; in other words, the own ethnic density concentrations for the BME women in the sample may not have been high enough to exert any protective effect against PND. Second, as suggested by Halpern \& Nazroo, ${ }^{3}$ variations in the ethnic density effect between ethnic groups may represent differences in the ability of some ethnic groups to protect the mental health of their members. In their national community survey, these authors demonstrated how the ethnic density effect for Pakistani people was not protective against mental ill health. ${ }^{3}$ It is even possible that the ethnic density effect could have negatively affected certain ethnic groups within our sample, but because all our ethnic groups were combined into one BME group, any negative effects for certain groups could have masked the overall putative protective effects for other BME groups.

\section{Strengths and limitations}

Our study, the first to demonstrate a significant effect in the association between ethnic density and PND, used structured, validated instruments and appropriate statistical methods that took into account geographical clustering and non-independence of observations. Furthermore, we were able to control for sociodemographic differences between the groups, and the assessment of ethnic density was conducted at the lowest level of geography, which most studies have not done, ${ }^{26}$ and included both own and overall ethnic density assessments.

However, the study had some caveats. First, although we demonstrate that there is a protective ethnic density effect against PND for White women in our sample, it is important to note that the effect size is small. Second, the study was based on a sample recruited from a single centre in London. Although the hospital centre covers a wide, socially heterogeneous area, the generalisability of our findings to other centres is uncertain. Moreover, excluding 
women with poor English fluency, who were unable to provide fully informed consent also altered the generalisability of our findings and may have introduced selection bias. However, as only $2 \%(n=63)$ of the approached sample was excluded based on this criterion, the impact of this would have been minimal. Third, we were unable to definitively measure depression and personality disorder and were instead reliant on screening measures, rather than clinical interviews. Although this has allowed us to collect data on this large sample of more than 2600 women, and both instruments have been validated extensively, ${ }^{13-22}$ this approach is less robust than direct interviews. Fourth, the prevalence rate of PND in our sample was relatively low compared with previously reported period prevalence rates in the UK. ${ }^{9}$ However, the reported rate of PND in this study was a point prevalence of moderate to severe depression, in a community sample, at 6 weeks postpartum. Since research shows that only $3-5 \%$ of new mothers develop moderate to severe PND, within the first 4-6 weeks after birth, ${ }^{41}$ the prevalence rate of PND in our sample is not especially low. ${ }^{41}$ Finally, the definitions of ethnicity used did not necessarily tap into notions of cultural identity: they did not represent religious affiliations or the first language spoken by the participants, both of which may have influenced the protective effects of ethnic density. Furthermore, our sample consisted of 16 ethnic groups, but the small numbers of participants in some groups limited our ability to examine fully the ethnic density effect separately in all these groups. Combining all BME women into one group represents another limitation, and may have masked any ethnic density effect, whether detrimental or protective, especially when the prevalence rates for both PND and personality dysfunction vary across BME groups, and particularly in comparison with the White population. Indeed, combining all BME women into one group may have masked the effects of factors that differ between groups, such as reasons for immigration, settlement patterns, cultural identity, family traditions and age structure.

\section{Implications and future research}

The results of this study provided some compelling evidence in support of the notion that higher own ethnic density was protective against PND for White women in London, and demonstrated the importance of social factors in the aetiology of the disorder. Future studies should examine the impact of language, religion, social capital, acculturation and nativity, which could all have ultimately contributed to the ethnic density effect. From a clinical point of view, ethnic density could help identify 'at risk' women during pregnancy: women living in areas where they feel isolated and alone could be offered more support during the postnatal period, and thus we propose that it would be potentially beneficial for midwives and doctors to ask pregnant women about the neighbourhood in which they live. Finally, although the mechanisms of the ethnic density effect in PND are not definitively clear, the findings of this study serve to underline the potential 'psychic shelter' function of ethnically dense neighbourhoods, ${ }^{39}$ and stress the importance of further research in the potential protective effects of ethnic density in different BME groups, in order also to inform social policies regulating dispersal and housing of immigrants and asylum seekers, especially if they are particularly vulnerable, such as pregnant women.

\section{Funding}

The study was funded by the Foundation for the Study of Infant Deaths. C.M.P. and P.M. are supported by the National Institute of Health Research (NIHR) Biomedical Centre for are supported by the National Institute of Health Research (NIHR) Biomedical Centre for
Mental Health at the South London and Maudsley NHS Foundation Trust and King's College London.

\section{Acknowledgements}

We thank all the women who gave their time to contribute to the study and the staff of King's College Hospital who helped to facilitate the recruitment of participants. Thanks also to Robin Schacht, Helen Davies and Laura Jones who assisted with recruitment and screening, and to Dr Jayati Das-Munshi for her advice on generating the ethnic density variables.

Andrea Du Preez, MSc, Psychological Medicine, Institute of Psychiatry, Psychology and Neuroscience, King's College London; Susan Conroy, MSc, Psychological Medicine, Institute of Psychiatry, Psychology and Neuroscience, King's College London; Susan Pawlby, MA, PhD, CPsychol, Psychological Medicine, Institute of Psychiatry, Psychology and Neuroscience, King's College London; Paul Moran, MD, MSC, MRCPsych, Institute of Psychiatry, Psychology and Neuroscience, King's College London; Carmine M. Pariante, MD, FRCPsych, PhD, Psychological Medicine, The James Black Centre, King's College London, UK

Correspondence: Carmine M. Pariante, MD, FRCPsych, PhD, Institute of Psychiatry, Psychology and Neuroscience, King's College London, Room 2-055, The James Black Centre, 125 Coldharbour Lane, London SE5 9NU, UK. Email: carmine.pariante@kcl.ac.uk

First received 10 Apr 2014, final revision 12 Feb 2015, accepted 13 Feb 2015

\section{References}

1 Faris RE, Dunham HW. Mental Disorders in Urban Areas: An Ecological Study of Schizophrenia and Other Psychoses. University of Chicago Press, 1939.

2 Halpern D. Minorities and mental health. Soc Sci Med 1993; 36: 597-607.

3 Halpern D, Nazroo J. The ethnic density effect: results from a national community survey of England and Wales. Int J Soc Psychiatry 2000; 46: 34-46.

4 Onozawa K, Kumar R, Adams D, Doré C, Glover V. High EPDS scores in women from ethnic minorities living in London. Arch Womens Ment Health 2003; 6: $51-5$.

5 Jayaweera H, Quigley MA. Health status, health behaviour and healthcare use among migrants in the UK: evidence from mothers in the Millennium Cohort Study. Soc Sci Med 2010; 71: 1002-10.

6 Crawford MJ, Rushwaya T, Bajaj P, Tyrer P, Yang M. The prevalence of personality disorder among ethnic minorities: findings from a national household survey. Personal Ment Health 2012; 6: 175-82.

7 Pickett KE, Shaw RJ, Atkin K, Kiernan KE, Wilkinson RG. Ethnic density effects on maternal and infant health in the Millennium Cohort Study. Soc Sci Med 2009; 69: 1476-83.

8 Coid J, Tyrer P, Roberts A, Ullrich S. Prevalence and correlates of personality disorder in Great Britain. Br J Psychiatry 2006; 188: 423-31.

9 Gavin NI, Gaynes BN, Lohr KN, Meltzer-Brody S, Gartlehner G, Swinson T. Perinatal depression: a systematic review of prevalence and incidence. Obstet Gynecol 2005; 106: 1071-83.

10 Hirschfeld RM. Personality disorders and depression: comorbidity. Depress Anxiety 1999; 10: 142-6.

11 Mulder RT. Personality pathology and treatment outcome in major depression: a review. Am J Psychiatry 2002; 159: 359-71.

12 Conroy S, Marks MN, Schacht R, Davies HA, Moran P. The impact of maternal depression and personality disorder on early infant care. Soc Psychiatry Psychiatr Epidemiol 2010; 45: 285-92.

13 Kroenke K, Spitzer RL, Williams JB. The PHQ-9: validity of a brief depression severity measure. J Gen Intern Med 2001; 16: 606-13.

14 Arroll B, Goodyear-Smith F, Crengle S, Gunn J, Kerse N, Fishman T, et al. Validation of PHQ-2 and PHQ-9 to screen for major depression in the primary care population. Ann Fam Med 2010; 8: 348-53.

15 Kocalevent RD, Hinz A, Brähler E. Standardization of the depression screener patient health questionnaire (PHQ-9) in the general population. Gen Hosp Psychiatry 2013; 35: 551-5.

16 Huang FY, Chung $\mathrm{H}$, Kroenke $\mathrm{K}$, Delucchi KL, Spitzer RL. Using the Patient Health Questionnaire-9 to measure depression among racially and ethnically diverse primary care patients. J Gen Intern Med 2006; 21: 547-52.

17 Kendrick T, Dowrick C, McBride A, Howe A, Clarke P, Maisey S, et al. Management of depression in UK general practice in relation to scores on depression severity questionnaires: analysis of medical record data. BMJ 2009; 338: b750.

18 Manea L, Gilbody S, McMillan D. Optimal cut-off score for diagnosing depression with the Patient Health Questionnaire (PHQ-9): a meta-analysis. CMAJ 2012; 184: 191-6.

19 Moran P, Leese M, Lee T, Walters P, Thornicroft G, Mann A. Standardised Assessment of Personality - Abbreviated Scale (SAPAS): preliminary 
validation of a brief screen for personality disorder. Br J Psychiatry 2003 183: 228-32.

20 Gorwood P, Rouillon F, Even C, Falissard B, Corruble E, Moran P. Treatment response in major depression: effects of personality dysfunction and prior depression. Br J Psychiatry 2010; 196: 139-42.

21 Fok M, Hotopf M, Stewart R, Hatch S, Hayes R, Moran P. Personality disorder and self-rated health: a population-based cross-sectional survey. J Pers Disord 2013; 119: 1-15.

22 Crawford MJ, Price K, Gordon F, Josson M, Taylor B, Bateman A, et al. Engagement and retention in specialist services for people with personality disorder. Acta Psychiatr Scand 2009; 119: 304-11.

23 Office for National Statistics. Ethnic Group Statistics. A Guide for the Collection and Classification of Ethnicity Data. HMSO, 2003.

24 Office for National Statistics. Census: People and Society; Ethnic group (data tables). London, United Kingdom: Office for National Statistics. ONS, 2001 (http://www.neighbourhood.statistics.gov.uk/dissemination/ datasetList.do\#10).

25 Office for National Statistics. Beginner's Guide to UK Geography - Super Output Areas (SOAS). ONS, 2007 (http://www.statistics.gov.uk/geography/ beginners_guide.asp).

26 Shaw RJ, Atkin K, Bécares L, Albor CB, Stafford M, Kiernan KE, et al. Impact of ethnic density on adult mental disorders: narrative review. Br J Psychiatry 2012; 201: 11-9.

27 Noble M, Wright G, Smith G, Dibben C. Measuring multiple deprivation at the small-area level. Environ Plan A 2006; 38: 169-85.

28 Fagg J, Curtis S, Stansfeld S, Congdon P. Psychological distress among adolescents, and its relationship to individual, family and area characteristics in East London. Soc Sci Med 2006; 63: 636-48.

29 Das-Munshi J, Becares L, Dewey ME, Stansfeld SA, Prince MJ. Understanding the effect of ethnic density on mental health: multi-level investigation of survey data from England. BMJ 2010; 341: c5367.
30 Stafford M, Becares L, Nazroo J. Objective and perceived ethnic density and health: findings from a United Kingdom general population survey. Am J Epidemiol 2009; 170: 484-93.

31 Karlsen S, Nazroo JY, Stephenson R. Ethnicity, environment and health: putting ethnic inequalities in health in their place. Soc Sci Med 2002; 55 1647-61.

32 Ecob R, Williams R. Sampling Asian minorities to assess health and welfare. $J$ Epidemiol Community Health 1991; 45: 93-101.

33 Shields MA, Wailoo A. Exploring the determinants of unhappiness for ethnic minority men in Britain. Scott J Polit Econ 2002; 49: 445-66.

34 Beck CT. Predictors of postpartum depression: an update. Nurs Res 2001; 50 : 275-85.

35 Robertson E, Grace S, Wallington T, Stewart DE. Antenatal risk factors for postpartum depression: a synthesis of recent literature. Gen Hosp Psychiatry 2004; 26: 289-95.

36 Lancaster CA, Gold KJ, Flynn HA, Yoo H, Marcus SM, Davis MM. Risk factors for depressive symptoms during pregnancy: a systematic review. Am J Obstet Gynecol 2010; 202: 5-14.

37 Propper C, Jones K, Bolster A, Burgess S, Johnston R, Sarker R. Local neighbourhood and mental health: evidence from the UK. Soc Sci Med 2005; 61: 2065-83.

38 Boydell J, van Os J, McKenzie K, Allardyce J, Goel R, McCreadie RG, et al. Incidence of schizophrenia in ethnic minorities in London: ecological study into interactions with environment. BMJ 2001; 323: 1336-8.

39 Kirkbride JB, Morgan C, Fearon P, Dazzan P, Murray RM, Jones PB. Neighbourhood-level effects on psychoses: re-examining the role of context. Psychol Med 2007; 37: 1413-25.

40 Kirkbride JB, Boydell J, Ploubidis GB, Morgan C, Dazzan P, McKenzie K, et al. Testing the association between the incidence of schizophrenia and social capital in an urban area. Psychol Med 2008; 38: 1083-94.

41 O'Hara MW, Swain AM. Rates and risk of postpartum depression - a metaanalysis. Int Rev Psychiatry 1996; 8: 37-54.

\section{extra a humbling experience}

\section{Owen Haeney}

I recently visited Uganda as a visiting clinician. After seeing the first patient, a child, my host asked about UK treatments. I admitted my uncertainty, since I had not treated a child for over a decade. I had a similar response when asked about an elderly man with dementia. The next patient presented in catatonia which prompted mutterings from me about the rarity of the condition at home. And another had psychiatric sequelae of a tropical disease, which left me amazed by the breadth of pathology. I confessed my awe at what Ugandan doctors had to know. 'Oh, I'm not a doctor, I'm a clinical assistant' he replied. 'I couldn't do what you do!' 